\title{
Teaching the Main State Languages in the System of Inclusive Education (On the Example of the Republic of Tatarstan)
}

\author{
Vladimir Belyaev \\ Kazan National Research Technical University named after \\ A. N. Tupolev - KAI \\ Kazan, Russian Federation \\ vlad_belyaev@list.ru
}

\author{
Gulnaz Sibaeva \\ Kazan State Power Engineering University \\ Kazan, Russian Federation \\ sigura2@mail.ru
}

\author{
Olga Maksimova \\ Kazan National Research Technical University named after A. N. Tupolev - KAI \\ Kazan Federal University \\ Kazan, Russian Federation
}

\begin{abstract}
With the growing number of people with disabilities and the need for their socialization, the role of their included education is growing. The article highlights the features of language teaching in the system of inclusive education of youth with disabilities. The specifics of learning the two main languages in the context of the language reform taking place in the national republics is considered. In the framework of inclusive education, the opportunities, advantages and difficulties of learning in two main languages of the Republic of Tatarstan (Russian Federation) of different groups of students with disabilities: dyslexic and mental illnesses, hearing impaired and deaf, visually impaired and blind, etc. The problem is the serious differences between the Turkic and Slavic languages in the field of grammar, in particular, in the construction of phrases, in the combination of the main verb with unions and particles, with auxiliary verbs and others. Difficulties in spelling, phonetics and syntax of the Russian and Tatar languages, quite overcome by most children with disabilities, become an obstacle for children with a number of mental illnesses who are unable to learn in an inclusive environment. As for diseases such as blindness, severe myopia, complete and partial hearing loss, cerebral palsy, serious cardiovascular diseases, lack of limbs and other diseases and physical limitations of children with disabilities, most of them do not interfere with inclusive language training.
\end{abstract}

Keywords: bilingualism, inclusive education, persons with disabilities, hearing impaired, visually impaired, learning spoken and written languages

\section{INTRODUCTION}

The increasing complexity of education in the information society creates both new educational opportunities for people with disabilities and certain difficulties for this type of socialization. One of the types of changes giving a similar ambivalent effect is the transition of Russian education from monolingual to multilingual. In the national republics of the Russian Federation in secondary schools, as a rule, universal compulsory education was introduced both in the state languages of the republics and in a foreign language. In Tatarstan, multilingual kindergartens and schools appeared, in which instruction is in Russian, Tatar and English. Reform of teaching the main state languages 2018-2019 requires new approaches to the implementation of bilingualism in inclusive education.

\section{METHODS}

Among the methods used in writing the article, the analysis of statistics and normative documents was applied.

The introduction of multilingualism undoubtedly poses new and complex challenges for the inclusive education of people with disabilities. According to the Federal State Statistics Service, since 2013, the number of disabled children in the country, with a general negative natural increase, increased by 102 thousand people. In the 2017-2018 academic year, the number of children with disabilities of preschool and school age health in the Republic of Tatarstan was 18.951 children: among them, children of preschool age - 4.305 people, school children - 14.646 children. Of the 4.305 children with disabilities of preschool age health registered with the educational authorities, the majority are children with speech impairment (36.2\%) and musculoskeletal system disorders $(22.9 \%)$. At the same time, there is an increase in the number of children with visual impairment over the year 
(5.3\%), speech impairment (6\%), cerebral palsy (7.5\%), and mental retardation $(12.8 \%)$.

Sociologists are increasingly interested in the peculiarities of teaching (and especially inclusive) children with disabilities. The level of disability of children and youth makes the problem of inclusive education relevant. The term "inclusion" was introduced into international practice at the World Conference on Education for Special Needs, held in 1994 under the auspices of UNESCO. Inclusive education in foreign theory and practice is seen as the joint training and education of children with normal and impaired development without any conditions and restrictions. Inclusive education as a social phenomenon involves the formation in society of a special culture of attitudes towards disability, towards people with disabilities, the creation of conditions that ensure socialization and the maximum possible self-realization of people with disabilities.

The 2006 UN Convention on the Rights of Persons with Disabilities, which enshrines the fundamental rights and freedoms of people with disabilities, was the first comprehensive human rights treaty of the 21 st century. In 2012, Federal Law № 46 of the Russian Federation "On Ratification of the Convention on the Rights of Persons with Disabilities" was adopted, which implies the creation of a material environment for the full life of a disabled person - a full member of society, the development of an inclusive education system.

\section{RESULTS}

At the same time, new problems caused by the complexity of education tasks, in particular, the introduction of multilingualism in national republics, require analysis of the specifics of teaching domestic (for example, Tatar-Russian) bilingualism among persons with disabilities.

People with disabilities can study in special educational institutions. This type of training has its own problems and achievements. Among the latter are a higher level of specialist defectologists with special professional training, an individual approach to students, the availability of an accessible environment around the institution and inside it, more free communication between students and the formation of peer groups. At the same time, it is more difficult for graduates of such educational institutions to fit into modern society, since they do not have adaptation skills among non-disabled people.

As a result of this, inclusive education, such a channel of socialization of children and youth with disabilities, is becoming increasingly popular. The positive features of this type of education include early and multi-component adaptation of people with disabilities, the formation of psychological confidence in them of their "normality", great opportunities for social advancement and, often, the emergence of tandems and even peer groups from people with disabilities and non-disabled.

With inclusive training of people with disabilities, the perception and understanding of different academic disciplines is carried out at an uneven pace and with varying levels of success. If the natural and technical sciences, based on the methods of scientism, quantification, on the verification of experience, behaviorism, on explanation, can be mastered in the presence of physical limitations of students (problems arise only in relation to observation and empirical comparison as methods of cognition), then, for example, linguistic disciplines give people with certain health limitations not so much problems as new opportunities.

Obviously, the study of two or more languages by people with disorders of the musculoskeletal system, without limbs, and even blind people, follows the same pattern as the development of the natural sciences. A completely different thing is with the hearing impaired and deaf and dumb. The fact is that people with hearing problems themselves learn the language of the deaf-mute, which for most peoples is not phonetic or morphological in nature, but primarily symbolic (when words of the same meaning, according to the accepted system, are represented by hands in the same way in all languages). The exception is the proper names and rarely used scientific terms, which are often duplicated in letters. Thus, for most parameters, hearing-impaired and deaf people have no problems translating words and sentences and mastering Latin, Arabic and Cyrillic letters. Therefore, the perception and understanding of other people's speech transposed through a person who speaks the language of the deaf, does not constitute a problem for this category of people with disabilities. The same scheme is used when speaking such people: the speaker - the translator into the language of the deaf-mute - the audience. For these reasons, more often than not, an intermediate link in the form of a translator is not necessary if the conversation is between people with hearing impairment and speaking different languages. As for the development of a written non-native language, it is quite possible to carry out it according to the rules common to all students. Thus, the mastery of bilingualism for this type of persons with disabilities both in educational institutions and outside them is easier and easier than for non-disabled people and does not cause any additional difficulties with inclusive education.

The opposite picture, as experience shows, looms with language training for the visually impaired and blind. The algorithm for studying a second or more languages for this category of persons with disabilities is the following: oral speech is mastered according to the general scheme, and as for reading and writing, computers and gadgets, the Internet and social networks are used here only in the presence of the Broille alphabet on keyboards in terms of writing texts. It is more difficult to perceive other people's texts: either a device is built into the gadget that allows you to convert written speech to spoken, or you need to create a device that converts the text written on the screen into Broille's alphabet. Such problems complicate the study of languages by the blind and visually impaired, especially with inclusive learning, when the pace of presenting new material in writing will be completely different for the blind and for non-disabled people.

As for other diseases and physical disabilities of persons with disabilities, most of them do not interfere with inclusive language training. The exception is only those who have graduated from auxiliary schools. However, the problems in learning languages by such people are not much different from 
the difficulties in mastering other academic disciplines. At the same time, people suffering from dyslexia and a number of mental diseases have their own difficulties in learning languages, especially written language, in some cases blocking the possibility of inclusive education.

Practice shows that children with a number of mental illnesses, unlike physical illnesses, are evaluated by parents of non-disabled people in modern Russia very ambiguously. So, on the global Internet, whole campaigns are regularly raised against the inclusive education of children with autism, mental retardation and a number of nervous diseases. Parents of nondisabled children indicate not only the impossibility of communication with such students, but also the negative impact of these children on the whole class and on their mastering of the main academic disciplines. This often leads to the rejection of such people with disabilities, to hatting and bullying by healthy children, which does not allow to develop communication skills and socialize a disabled child when using an inclusive environment. Because of this, children with autism, mental retardation, have to change their regular schools, or look for a specialized school without an inclusive environment. At the same time, the attitude of ordinary children and their parents to students suffering from mental illness is largely determined by the degree of the disease.

All of the above causes problems in the mastering of the two main languages of the Republic of Tatarstan by children with disabilities with inclusive education. A number of mental diseases at this stage in the development of medicine and pedagogy in principle do not allow the study of two languages, because many of these children begin to get confused in the application of a particular vocabulary and in the phrases construction. So, the absence of the genus category in the Tatar language, facilitating the mastering of this language, makes it difficult to use the genus in the Russian language in the future (as a result, the expressions "my mother" ("moy mama", girls with the names "Lily of the Valley" and boys with the names "Lilac" appear; despite the fact that mother and lilac in Russian are feminine words, and the lily of the valley is masculine). It is difficult to switch from one language to another one and different word management, when in Russian the flexion is added to a other word of two mutual related words than in the Tatar language (for example, Wolfberry - in Russian the word Wolf changes, in Tatar Berry). The difference in syntax, and the availability in the Tatar language of a number of sounds that do not exist in Russian also complicate the both language` acquisition.

Difficulties in orthoepy, orthography, phonetics and syntax of the Russian and Tatar languages, which are quite overcome by most children with disabilities, become a serious obstacle for children with a number of mental illnesses. Such children at this stage of social development are absolutely unable to learn in an inclusive environment.

\section{DISCUSSION}

This problem has not yet received proper analysis in the sociological literature. Thus, it is possible to allocate the works devoted to bilingualism in training [1-11]. However, they do not specifically highlight the problems of people with disabilities.

The scientific works of this subject include works that analyze the problems of school education of children with disabilities [14-17]. There are also works in which the issues of higher education of youth with disabilities are studied [15, 18-23]. Standing apart are works analyzing the willingness of teachers to carry out inclusive education [15, 24-28]. In sociology, the problems of learning foreign languages by persons with disabilities are posed [29-32]. In the scientific literature, questions are increasingly being raised of revealing the level of tolerance / intolerance of society towards students with disabilities [33-35]. An analysis of both scientific articles and the practice of introducing inclusive education in schools allows us to conclude that there is a differentiation of the opinions of parents and teachers on the possibility and usefulness of co-education of children with and without health restrictions, depending on the type of disease and the degree of its impact on the body.

\section{CONCLUSIONS}

Thus, inclusive education can be interpreted by science and understood by society as a way out of multi-component discrimination of one of the socially disadvantaged groups of society. In this case, the channels for overcoming this type of social deprivation will be multiple: both coinciding with the analogues introduced in other groups, and specific. The types of health restrictions themselves are depending on the vector and the strength of their impact on language acquisition: on contributing (for most parameters for the deaf), multidirectional (for the blind) and inhibitory (a number of other health restrictions). The authors typologize the kinds of health restrictions, depending on the vector and the strength of their impact on language acquisition: on assisting (for most parameters for the deaf), multidirectional (for the blind) and inhibitory (a number of other health restrictions). The difference in the grammar of the Russian and Tatar languages, overcome by most disabled children, becomes an insurmountable obstacle for children with a number of mental illnesses, and more difficult for patients with dyslexia. Along with the objective prerequisites for withdrawing from social exclusion formed by the state, the subjective attitude of society, classmates, classmates, teachers and parents towards people with disabilities and their inclusion in the learning process can play an equally important role.

\section{ACKNOWLEDGMENTS}

This article was prepared with financial support from the Russian Foundation for Basic Research and the Government of the Republic of Tatarstan in the framework of project № 18-411-160011 "Social and information-network aspects of the transformation of bilingualism policy in the Republic of Tatarstan in the context of maintaining ethnic tolerance of the population". 


\section{REFERENCES}

[1] V. A. Belyaev and G. R. Shibaeva, "Divergence of motivation of the bilingual intelligentsia of the Republic of Tatarstan", Journal of Economics, law and sociology, 2019, no. 2, pp. 90-96.

[2] L. V. Efremenko, "The Study of bilingualism at the present stage and features of children's bilingualism", Bulletin Of The Bonfire, state University, Ser. Pedagogy. Psychology. Sotsiogenetiki, 2018,.vol. 4, no. 3, pp. 178-180.

[3] K. V. Saldaeva, "The The main approaches to understanding the term "bilingualism" in modern science", Modern research, 2018, no. 7 (11), pp. 50-52.

[4] N. G. Fersman and M. P. Agafonova, "Bilingualism as a phenomenon of intercultural communication", Kant, 2018, no. 4 (29), pp. 89-96.

[5] A. A. Chikvaidze, "Interaction of language cultures in bilingualism", Actual problems of germanistics, romanistics and Russian studies, 2016, no. 2, pp. 152-159.

[6] P. Romanowski and M. Jedynak, "Current Research in Bilingualism and Bilingual Education", Multilingual Education, Springer, Netherlands, 2018, vol.26, 241 p.

[7] O. Maximova, V. Belyaev, and A.Mingazova, "Generational features of ethnic personal identification in a MultiEthnic society", Astra Salvensis 6, 2018, pp. 443-451.

[8] C. Eben and M. Declerck, "Conflict monitoring in bilingual language comprehension?", Evidence from a bilingual flanker task, Language cognition and neuroscience, 2019, vol.34, issue 3, pp. 320-325.

[9] A. Marini, N. Eliseeva, and F. Fabbro, "Impact of early second-language acquisition on the development of first language and verbal short-term and working memory", International Journal of bilingual education and bilingualism, 2019, vol. 22, issue 2, pp. 165-176.

[10] O. A. Maximova and V. A. Belyaev, "Generational indigenation in a multi-ethnic and religious society", Tatarstan, Russia, Opcion, 2017, 33 (84), pp. 38-64.

[11] A. Sampedro and J. Pena, "The Effect of Bilingualism Level on Creative Performance during Preadolescent Period", Spanish journal of psychology, 2019, vol. 22, art. E12.

[12] O. A. Maximova, V. A. Belyaev, O. V. Laukart-Gorbacheva, and I. V. Larionova, "Intergenerational discourse on the problems of Russian education and creation of bilingual environment", European Research Studies Journal, 2018, 21 (4), pp. 805-817.

[13] S. Surrain and G. Luk, "Describing bilinguals: A systematic review of labels and descriptions used in the literature between 2005-2015", Bilingualism-language and cognition, 2019, vol. 22, issue 2, pp. 401415.

[14] N. N. Malofeev, "Children with developmental disabilities in secondary school: General and special requirements for the results of education", Education and training of children with developmental disabilities, Moscow: Schools, Press, 2010, no. 5, pp. 6-11.

[15] T. V. Timokhina, "Prospects of development of the system of professional training of specialists to work with children with disabilities in high school", Prospects of science and education, Voronezh: The Ecologist.help-2015, no. 2 (14), pp. 91-95.

[16] N. D. Shmatko, "Joint education and training of children with disabilities and normally developing preschoolers", Education and training of children with developmental disabilities, 2010 , no. 5, pp. 12 19.

[17] E. R. Yarskaya-Smirnova, D. I. Prisyazhnyuk, V. N. YarskayaSmirnova, and A. A. Baranova, "Social inclusion and cohesion in school education: policy and practice", Socio-cultural practices of cohesion in modern societies, Moscow: University book, 2015, chapter 4, pp. 250283.
[18] E. V. Belozerova, "The Accessibility of professional education for people with disabilities in the Russian regions", Education for all: ways to integration: collection of scientific works.art., SGTU, Saratov, 2003, pp. 16-21.

[19] D. V. Zaitsev, Y. Yu. Pravkina, and O. V. Zaitseva, "Sociocultural tolerance in the context of remote employment of people with disabilities", The Culture of Tolerance in a Context of Globalization: Methodology of Research, Reality and Prospect, 2016, pp. 43-47.

[20] G. G. Karpova, "Accessibility of higher education for disabled people", Accessibility of higher education in Russia, Independent Institute of social policy, Moscow: Pomatur, 2004, pp. 330-376.

[21] "International Congress of practitioners of inclusive education, dedicated to the 20th anniversary of education of persons with disabilities", the University of management "TISBI": Final materials, Kazan: TISBI University of management, 2016, $320 \mathrm{p}$.

[22] E. K. Naberushkina, "Guidelines for the development of inclusion in the space of higher education", Society, Inclusion, 2017, no. 4 (32), pp. 18 28.

[23] J. Hall and T. Tinklin, "Students with disabilities and higher education", Journal of social policy research, 2004, vol. 2, no. 1, pp. 115-126.

[24] T. G. Zubareva, "Development of professional competence of specialists in the field of inclusive education", Siberian pedagogical journal, 2009, no. 4, pp. 297-310.

[25] E. N. Kutepova, "Readiness of the teacher to activity in the conditions of inclusive practice", Inclusive education: practice, research, methodology: collection of materials II international science, pract.Conf., executive editor: S. V. Alekhina, Moscow, 2013, pp. 588592.

[26] O. Maximova, V. Belyaev, O. Laukart-Gorbacheva, L. Nagmatullina, and G. Hamzina, "Russian education in the context of the third generation universities` discourse: Employers' evaluation", International Journal of Environmental and Science Education, 2016, 11 (16), pp. 9101-9112.

[27] Yu. V. Selivanova and D. V. Zaitsev, "Organizational and methodological aspects of support of students with disabilities in professional education", Bulletin of Chelyabinsk state University, Ser. Psychology and pedagogy, 2015, no. 1 (1), pp. 97-103.

[28] A. S. Sirotyuk, "Education of a child in an inclusive environment. Methods, diagnostics", Moscow: Sphere, 2014, 128 p.

[29] A. V. Konyushko, "Inclusive teaching a foreign language to students with disabilities", Scientific Palette, 2018, no. 4 (22), 3 p.

[30] N. G. Pribylova and G. V. Sorokov, "Inclusive foreign language education of children with visual impairments", Secondary vocational education, 2017, no. 8, pp. 51-53.

[31] G. V. Sorokovs and L. R. Denisova, "Teaching a foreign language to younger students in an inclusive education environment", Educational Psychology in a Multicultural Space, 2016, no. 34 (2), pp. 132-136.

[32] V. M. Timkina, "Inclusive education of children with disabilities in the system of teaching foreign languages", XLVI final student scientific conference of the Udmurt State University Materials of the All-Russian Conference, 2018, pp. 444-447.

[33] S. Drobysheva, "Attitude to the disabled-an indicator of the moral health of society", Man and Labor, 2003, no. 10, pp. 12-15.

[34] E. A. Martynova, "Social and pedagogical bases of construction and functioning of the system of accessibility of higher education for persons with disabilities", Chelyabinsk: Chelyabinsk State University, 2002.

[35] V. A. Belyaev and G.R. Sibaeva, "The Specifics of the Bilingualism Implementation in the Field of Inclusive Education", Bulletin of Economics, Law and Sociology, 2019, no. 3, pp. 93-96. 